\title{
Monopoly Behaviour with Speculative Storage
}

\author{
Sébastien Mitraille \\ Henry Thille \\ Toulouse Business School \\ University of Guelph
}

January 18,2008

\author{
University of Guelph \\ Working Paper 2008-5
}

\begin{abstract}
We analyze the effects of competitive storage when the production of the good is controlled by a monopolist. The existence of competitive storers serves to reduce the monopolist's effective demand when speculators are selling and to increase it when they are buying. This results in the monopolist manipulating the frequency of stock-outs, and hence, the price-smoothing effects of competitive storage. We use a two-period model to show that there is a lower probability of a stock-out under a monopolist than in a perfectly competitive market. We find that there exist states of the world in which the monopolist prices higher on average than what would occur in the absence of speculators. We then extend the model to an infinite horizon to examine the implications for price volatility using collocation methods to approximate both the expected future price and the expected value function. We confirm that stock-outs occur less frequently under the monopolist, even though price is more volatile. We also demonstrate that while free entry by speculators does reduce the gap in price volatility, it does not remove it.
\end{abstract}




\section{Introduction}

Competitive storage has the potential to be an important influence on the behaviour of firms with market power. For many storable commodities, production is undertaken in concentrated industries. Examples include petroleum, natural gas, nickel, $\operatorname{tin}^{1}$, and aluminum. Although the storage technology differs across these commodities, they generally share the feature that storage by intermediaries is not precluded. For the non-ferrous metals traded on the London Metal Exchange, it is relatively simple to store the commodity as the exchange organizes storage facilities. In effect, any individual can purchase and store these metals. Storage of commodities like natural gas is more complicated, although deregulation in the U.S.A. over the past couple of decades has resulted in entry of independent storage firms. ${ }^{2}$ In this case, storage capacity is potentially an important factor on the effects of speculation on equilibrium. For all of these commodities, it is natural to ask how speculative storage will affect the use of market power. We analyze this question by examining the effects that competitive storage has on the behaviour of a monopolist/cartel in order to highlight any incentives that firms with market power have to influence speculative activity, and consequently affect the distribution of prices. Speculation can have two different effects on the residual demand faced by firms. When they are selling their stocks, speculators are competing with producers, reducing residual demand. Conversely, when speculators are accumulating inventory, they increase residual demand. Firms with market power then have an incentive to lower price in order to induce speculative purchases, but this comes at the cost of increased speculative sales in the future. In this paper, we demonstrate that these incentives do result in changing the way in which speculative activity affects the distribution of prices.

One can view production and storage as sequential stages of activity for which agents that store the good need not be the same as those that produce it, in this way allowing for different degrees of market power at different points in the supply chain. Much of the work that has been done on the effects of speculative storage imposes perfect competition at both the production and storage stages. The theory under these conditions has been well established by Samuelson [11], Newbery and Stiglitz [10], Scheinkman and Schechtman [12], Williams and Wright [14], and Deaton and Laroque [2]. As this body of work demonstrates, the constraint that inventories be non-negative causes the distribution of price to have two regimes: one corresponding to positive inventories being held, and one corresponding to stock-outs.

The effects of market power in the storage activity has been examined by Newbery [9], Williams and Wright [14], and McLaren [7]. Newbery [9] shows that a firm with monopoly power over storage will smooth harvest fluctuations more than a competitive storage sector

\footnotetext{
${ }^{1}$ The International Tin Agreement collapse in 1985 was partly attributable to speculators' behaviour (Anderson and Gilbert [1])

${ }^{2}$ As of 2005 , independent storage operators accounted for $13 \%$ of storage capacity in the U.S.A.(Energy Information Association [4]). This represented a substantial increase over just a few years prior.
} 
would. In an extension to his basic model, he allows the monopolist to control the harvest and demonstrates that the monopolist's residual demand is kinked when the price causes competitive storage to occur, although he does not solve this version of model. The model we develop in this paper also generates this type of residual demand for the monopolist. McLaren [7] examines an oligopoly in the storage activity and finds that in a Markovperfect equilibrium, the oligopoly smooths price less than perfectly competitive firms do. In contrast to these papers that examine market power in storage with competitive production, we examine market power in production with competitive storage.

A market in which both production and storage occur under imperfect competition is examined in Thille [13]. Cournot duopolists are able to store their output, giving them a strategic motive to use inventories to reduce marginal production costs. It is shown that firms with market power make less use of inventories than is efficient, resulting in more volatile prices in the face of demand fluctuations and less volatile prices in the face of cost fluctuations. Storage by competitive speculators was not considered in this model. In contrast, we allow for competitive storage but simplify the production side by focusing on monopoly production.

In order to analyse the effects of competitive speculation on a firm with market power, we separate production and storage completely by not allowing the monopolist to store the good, so that any storage that occurs must be done by the competitive storers. However, the monopolist is able to induce storage by manipulating price to induce speculative purchases or sales. There are two broad questions that we ask. First, how does the frequency of stock-outs and the distribution of price differ under monopoly as opposed to competitive production? Second, how does speculation affect the behaviour of a monopolist? The answers to these questions has implications for the distribution of price that we expect to observe. We find that stockouts occur less frequently under the monopolist than is efficient and that speculation leads to smoother prices than occurs under the static monopoly, although not as smooth as is efficient. An interesting sub-case arises in which the monopolist keeps price at the threshold that just induces a stockout in order to not face competition from speculators in the next period. This results in an average price that is slightly higher when speculation is possible than which occurs under a static monopoly. In what follows, we first present the general model. We then examine a two period model for which we can get a closed form solution, after which we analyze an infinite horizon model using numerical techniques.

\section{The Model}

We consider a discrete time economy with an horizon $T$ which may be infinite. In every period $t=1, \ldots, T$, consumers have a demand $D_{t}$ for an homogeneous and non-perishable product they can buy on a spot market. We assume that consumers cannot store, and therefore cannot sell the product. Consumers' demand in period $t, D_{t}$, is a decreasing 
function of the spot price $p_{t}$, and is an increasing function of a random state $a_{t}$ which represents consumers' maximum willingness to pay for the product in this period. We assume that consumers' demand is a linear function of $p_{t}$ and $a_{t}$, given by

$$
D_{t}=\max \left\{a_{t}-p_{t}, 0\right\}
$$

where the random state $a_{t}$ is drawn by Nature at the beginning of period $t$ and known to every participant of the spot market before decisions are made. All market participants have rational expectations over future demand conditions, but these conditions are not known before they are realized: only the distribution of the future random states is known. We assume that random states $\left\{a_{t}\right\}_{t=1, \ldots, T}$ are independently and identically distributed according to a time-invariant cumulative distribution function $F$.

In every period $t$ a fringe of independent storers, the competitive speculators, are able to buy or sell on the spot market, and are able to store the product. Let $x_{t}$ denote the position of speculators on the spot market of period $t$ : if $x_{t}$ is positive, then speculators selling the product, while if $x_{t}$ is negative speculators are buying the product. Speculators are able to store the product at a unit cost of $w$ per period and we denote $h_{t}$ the amount of storage available at the beginning of period $t$. Inventories do not depreciate. The transition equations for inventories is then

$$
h_{t+1}=h_{t}-x_{t}
$$

Negative inventories are not allowed and an aggregate storage capacity of $\bar{h}$ that cannot be overcome is available. Therefore in every period speculators position must satisfy

$$
x_{t} \in\left[h_{t}-\bar{h}, h_{t}\right]
$$

Finally, we assume that final inventories, $h_{T+1}$, can be destroyed at no cost. Let the discount factor be $\delta \leq 1$, and let $E_{t}$ denote the expectation operator conditional on the information available in period $t$, the payoffs to competitive speculators from the sequence of aggregate sales are equal to

$$
\Pi_{0}^{S}=E_{0} \sum_{t=0}^{T} \delta^{t}\left(p_{t} x_{t}-w h_{t}\right) .
$$

In every period $t$, a monopolist sets a price $p_{t}$ and produces output $q_{t}$ using a decreasing returns to scale technology. The production technology is described by a convex cost function, assumed to be

$$
C\left(q_{t}\right)=\frac{c}{2} q_{t}^{2},
$$

where the rate of increase of the marginal cost, $c$, is constant and equal in every period. The monopolist cannot store its output, but due to the convex production costs is interested 
in storage. At the price he chooses, the monopolist has to serve the demand addressed to him. Its aggregate profit ex-ante is equal to

$$
\Pi_{0}^{m}=E_{0} \sum_{t=0}^{T} \delta^{t} \pi_{t}^{m}
$$

where $\pi_{t}^{m}=\left(p_{t} q_{t}-\frac{c}{2} q_{t}^{2}\right)$ and the quantity produced, $q_{t}$, must equal the total quantity demanded,

$$
q_{t}=-x_{t}+D_{t}
$$

\section{Analysis}

As is well known (see for example Williams and Wright [14]), in most cases it is not possible to obtain closed form expressions for the equilibrium outcomes due to the dependence of the solution on the expected future price. In this section, we discuss the general form of the solution, which forms the base underlying our solutions to the two-period and infinite horizon cases.

\subsection{The behaviour of speculators}

Price-taking speculators determine their position as follows. If the current spot price is strictly lower than the discounted expected price of next period minus the discounted storage cost, speculators wish to store as much as possible, resulting in storage equal to their capacity, $\bar{h}$. As they are capacity constrained, equilibrium prices and speculative sales satisfy the following complementarity condition:

$$
p_{t}-\delta E_{t}\left[p_{t+1}\right]+\delta w<0 \quad \Rightarrow \quad x_{t}=h_{t}-\bar{h}
$$

In this case we will say that the market is in a capacity regime.

Similarly if the current spot price is strictly higher than the discounted expected price of next period minus the discounted storage cost, then speculators wish to sell as much as possible. As negative inventories are not allowed, equilibrium prices and speculative sales satisfy the following complementarity condition:

$$
p_{t}-\delta E_{t}\left[p_{t+1}\right]+\delta w>0 \quad \Rightarrow \quad x_{t}=h_{t}
$$

In this case we will say that the market is in a stock-out regime.

Finally if the current spot price is exactly equal to the discounted expected future price minus the discounted storage cost, that is if $p_{t}=\delta E_{t}\left[p_{t+1}\right]-\delta w$, then speculators are indifferent between storing and selling. Speculative sales are determined to ensure market clearing at this price, i.e., $q_{t}=a_{t}-p_{t}-x_{t}$ and $p_{t}=\delta E_{t}\left[p_{t+1}\right]-\delta w$. As the expected future price is a function of the state variables $\left(a_{t}, h_{t}\right)$, speculative sales in this smoothing regime 
are a function of the state and of the quantity supplied $q_{t}$. This dependence on $q_{t}$ implies that future inventories are influenced by $q_{t}$. By our assumption of IID demand shocks, expected next-period price is independent of the current realization of the demand shock, consequently, we define $g\left(h_{t+1}\right) \equiv E_{t}\left(p_{t+1}\right)$. Using this notation we have

$$
h_{t}-h_{t+1}=a_{t}-q_{t}-\delta g\left(h_{t+1}\right)+\delta w,
$$

which defines $h_{t+1}$ as an implicit function of $q_{t}$. Define this function as $h_{t+1}=\psi\left(q_{t} ; a_{t}, h_{t}\right)$.

Speculative sales are then given by

$$
x_{t}= \begin{cases}h_{t}-\bar{h} & \text { if } p_{t}<p_{\ell} \\ h_{t}-\psi\left(q_{t} ; a_{t}, h_{t}\right) & \text { if } p_{\ell} \leq p_{t} \leq p_{u} \\ h_{t} & \text { if } p_{t}>p_{u}\end{cases}
$$

Continuity implies that the threshold prices, $p_{\ell}$ and $p_{u}$, are given by

$$
p_{\ell}=\delta g(\bar{h})-\delta w
$$

and

$$
p_{u}=\delta g(0)-\delta w
$$

The quantities that correspond to these two bounds are

$$
q_{\ell t}=a_{t}-h_{t}-p_{u}=a_{t}-h_{t}-\delta g(0)+\delta w
$$

and

$$
q_{u t}=a_{t}-h_{t}+\bar{h}-p_{\ell}=a_{t}-h_{t}+\bar{h}-\delta g(\bar{h})+\delta w
$$

\subsection{The behaviour of the monopolist}

We can now express inverse residual demand faced by the monopolist as

$$
P\left(q_{t} ; a_{t}, h_{t}\right)= \begin{cases}a_{t}-q_{t}-h_{t}+\bar{h} & \text { if } q_{t}>q_{u} \\ \delta g\left(\psi\left(q_{t} ; a_{t}, h_{t}\right)\right)-\delta w & \text { if } q_{t} \in\left[q_{\ell}, q_{u}\right] \\ a_{t}-q_{t}-h_{t} & \text { if } q_{t}<q_{\ell}\end{cases}
$$

Given $g\left(h_{t+1}\right)=E_{t}\left[p_{t+1}\right]$, we can solve for the monopolist's optimal output in period $t$, also a function of the state vector. Define this function as $f\left(a_{t}, h_{t}\right)$. Even though the monopolist has no direct control over the future state, it still faces a dynamic optimization problem since it can influence the level of inventories that speculators carry forward into 
the next period via its influence on price. The Bellman equation for the monopolist's problem is

$$
V^{m}\left(a_{t}, h_{t}\right)=\max _{q_{t}}\left\{P\left(q_{t} ; a_{t}, h_{t}\right) q_{t}-\frac{c}{2} q_{t}^{2}+\delta E_{t} V^{m}\left(a_{t+1}, h_{t+1}\right)\right\}
$$

subject to $h_{t+1}=h_{t}-x_{t}$. There are three cases to be analyzed corresponding to the three cases in (16).

1. Stock-out regime, $q_{t}^{*}<q_{\ell t}$ or $p_{t}^{*}>p_{u}$ : Here, speculators sell their entire stock in $t$, so $h_{t+1}=0$ and the monopolist's choice of output has no influence on next period's state. Hence, the optimal output is that which maximizes its static profit with $x_{t}=h_{t}$ :

$$
q_{t}^{*}=\frac{a_{t}-h_{t}}{2+c} \equiv f_{1}\left(a_{t}, h_{t}\right)
$$

If $q_{t}$ is chosen to be in this region, the value for the monopolist is

$$
v_{1}\left(a_{t}, h_{t}\right)=\frac{\left(a_{t}-h_{t}\right)^{2}}{2(2+c)}+\delta E_{t} V^{m}\left(a_{t+1}, 0\right)
$$

2. Capacity regime, $q_{t}^{*}>q_{u t}$ or $p_{t}^{*}<p_{\ell}$ : In this case, speculators purchase and carry the maximal amount of stocks into the next period: $h_{t+1}=\bar{h}$. Since this means that next periods speculative stocks are unaffected by changes in the monopolist's output, the optimal output for the monopolist is that which maximizes its static profit, given $x_{t}=h_{t}-\bar{h}$ :

$$
q_{t}^{*}=\frac{a_{t}-\left(h_{t}-\bar{h}\right)}{2+c} \equiv f_{3}\left(a_{t}, h_{t}\right)
$$

If $q_{t}$ is chosen to be in this region, the value for the monopolist is

$$
v_{3}\left(a_{t}, h_{t}\right)=\frac{\left(a_{t}-\left(h_{t}-\bar{h}\right)\right)^{2}}{2(2+c)}+\delta E_{t} V^{m}\left(a_{t+1}, \bar{h}\right)
$$

3. Smoothing regime, $q_{t}^{*} \in\left[q_{\ell t}, q_{u t}\right]$ or $p_{t}^{*} \in\left[p_{\ell}, p_{u}\right]$ :

For this intermediate case, $p_{t}=\delta g\left(\psi\left(q_{t} ; a_{t}, h_{t}\right)\right)-\delta w$, so $q_{t}^{*}$ solves

$$
\max _{q_{t}}\left\{\delta\left(g\left(\psi\left(q_{t} ; a_{t}, h_{t}\right)\right)-w\right) q_{t}-\frac{c}{2} q_{t}^{2}+\delta E_{t} V^{m}\left(a_{t+1}, h_{t+1}\right)\right\}
$$

subject to $h_{t+1}=h_{t}-x_{t}$. In this region, $q_{t}$ and $x_{t}$ are related by the requirement that $p_{t}=\delta\left(g\left(\psi\left(q_{t} ; a_{t}, h_{t}\right)\right)-w\right)$ or

$$
a_{t}-q_{t}-x_{t}=\delta\left(g\left(\psi\left(q_{t} ; a_{t}, h_{t}\right)\right)-w\right) .
$$


Solving for $x_{t}$, we can write the evolution of inventories as

$$
h_{t+1}=h_{t}-a_{t}+q_{t}+\delta\left(g\left(\psi\left(q_{t} ; a_{t}, h_{t}\right)\right)-w\right)
$$

which highlights the influence that the monopolist now has on the future state. For an interior optimum in this region, the following necessary condition must hold:

$$
\delta g\left(\psi\left(q_{t} ; a_{t}, h_{t}\right)\right)-\delta w-c q_{t}+\delta q_{t} \frac{\partial g\left(\psi\left(q_{t} ; a_{t}, h_{t}\right)\right)}{\partial q_{t}}+\delta \frac{\partial E_{t} V^{m}\left(a_{t+1}, h_{t+1}\right)}{\partial q_{t}}=0
$$

with $h_{t+1}$ given by (24). The last two terms on the left hand side are the effects that variation in output have on expected future price and value due to the influence on future inventories. Let $f_{2}\left(a_{t}, h_{t}\right)$ denote optimal production and $v_{2}\left(a_{t}, h_{t}\right)$ the corresponding value in this region.

To summarize this analysis, the monopolist's production in $t$ will be given by one of the three functions, $f_{1}, f_{2}$ or $f_{3}$. Which function is optimal is determined by the value obtained under each one. Consequently

$$
V^{m}\left(a_{t}, h_{t}\right)=\max \left[v_{1}\left(a_{t}, h_{t}\right), v_{2}\left(a_{t}, h_{t}\right), v_{3}\left(a_{t}, h_{t}\right)\right]
$$

Note that the functional form of $v_{1}$ and $v_{3}$ are known. Since $a_{t}$ is independently distributed, they are quadratic functions of $a_{t}$ and $h_{t}$ that are known up to a constant term, $E_{t} V^{m}\left(a_{t+1}, 0\right)$ for $v_{1}$ and $E_{t} V^{m}\left(a_{t+1}, \bar{h}\right)$ for $v_{3}$. Clearly, the difficulty lies in determining the solution in the smoothing region as it requires the evaluation of the composition of two unknown functions: the price expectation function, $g()$ and the equilibrium carry-out function, $\psi()$. In the next section, we restrict the time horizon to two periods for which we can obtain a closed-form solution. Following that, we examine numerical solutions to the infinite horizon version of the model.

\section{Two period horizon}

As a first step in our analysis of the model described in the previous section we examine the equilibrium when there are only two periods. Although restrictive, this exercise has the advantage that a closed-form solution can be obtained

In this section, we assume that the distribution of the demand intercept has support bounded away from zero. Define $\underline{a}$ to be the lower bound of the support. We maintain the following assumption:

Assumption 1 Speculators are small: $\bar{h}<\underline{a}$.

Assuming that speculators storage capacity is limited compared to the minimal demand seems realistic in practice and is made to ensure that selling the maximal amount of 
inventories cannot imply that consumers are satiated, in which case the market price, and therefore the gross return of speculation, would be equal to zero.

In the second period speculators have inventories of $h_{2}$ available. Since the storage cost is sunk at this point and they are price-takers, they will sell their entire stock as long as the market price for the product is non-negative. Under Assumption 1, speculative inventories can never be such that a stock-out in the second period causes the spot price to be zero. Profits to speculators in period two are thus $\left(p_{2}-w\right) h_{2}$. In the first period, speculators have $h_{1}$ stocks available and choose sales as described by (11).

\subsection{Perfect competition}

Suppose that production were undertaken by perfectly competitive firms whose aggregate marginal cost function is the same as the monopolists: $c q_{t}$. In this situation, the competitive supply function each period is equal to $S_{t}\left(p_{t}\right)=p_{t} / c$. As speculators sell $h_{2}$ on the second period market, demand in the second period is $D_{2}\left(p_{2} ; a_{2}, h_{2}\right)=a_{2}-p_{2}-h_{2}$. Under Assumption 1 non-negative prices exist for which demand is positive. The intersection between the competitive demand and the competitive supply gives

$$
p_{2}^{c}=\beta^{c}\left(a_{2}-h_{2}\right)
$$

where $\beta^{c} \equiv c /(1+c)$.

Given this expression for the second period price, it is immediate that $g^{c}\left(h_{2}\right) \equiv E_{1}\left(p_{2} \mid h_{2}\right)=$ $\beta^{c}\left(E(a)-h_{2}\right)$. From this, we have the price thresholds (12) and (13):

$$
p_{\ell}^{c}=\delta g^{c}(\bar{h})-\delta w=\delta \beta^{c}(E(a)-\bar{h})-\delta w
$$

and

$$
p_{u}^{c}=\delta g^{c}(0)-\delta w=\delta \beta^{c} E(a)-\delta w .
$$

We now need to determine the level of speculative sales, $x_{t}$, undertaken when we are in a smoothing regime: $p_{1} \in\left[p_{l}^{c}, p_{u}^{c}\right]$. Since $p_{1}=\delta\left(g^{c}\left(h_{2}\right)-w\right)$, using our expression for $g^{c}\left(h_{2}\right)$, we can solve for

$$
h_{2}=E(a)-\left(w+\frac{p_{1}}{\delta}\right) / \beta^{c}
$$

Using $h_{2}=h_{1}-x_{1}$, we have

$$
x_{1}=h_{1}-E(a)+\left(w+\frac{p_{1}}{\delta}\right) / \beta^{c} .
$$

Demand net of speculation is consequently equal to

$$
D_{1}\left(p_{1} ; a_{1}, h_{1}\right)= \begin{cases}a_{1}-h_{1}-p_{1}+\bar{h} & \text { if } p_{1}<p_{l}^{c} \\ a_{1}-h_{1}-p_{1}+E(a)-\left(w+\frac{p_{1}}{\delta}\right) / \beta^{c} & \text { if } p_{1} \in\left[p_{l}^{c}, p_{u}^{c}\right] \\ a_{1}-h_{1}-p_{1} & \text { if } p_{1}>p_{u}^{c}\end{cases}
$$


The competitive equilibrium can be obtained from the intersection of this demand with competitive supply, which we summarize as:

Proposition 1 Under Assumption 1, and for a given $\left(a_{1}, h_{1}\right)$, the equilibrium under perfect competition is characterized as follows:

1. (Stock-out regime) If $\beta^{c}\left(a_{1}-h_{1}\right)>\delta \beta^{c} E(a)-\delta w$, then

$$
p_{1}^{c}=\beta^{c}\left(a_{1}-h_{1}\right), \quad p_{2}^{c}=\beta^{c} a_{2}
$$

2. (Smoothing regime) If $\beta^{c}\left(a_{1}-h_{1}\right) \leq \delta \beta^{c} E(a)-\delta w$ and $\beta^{c}\left(a_{1}-h_{1}+\bar{h}\right) \geq$ $\delta \beta^{c}(E(a)-\bar{h})-\delta w$, then

$$
p_{1}^{c}=\frac{\delta \beta^{c}\left(a_{1}-h_{1}+E(a)\right)-\delta w}{1+\delta}, \quad p_{2}^{c}=\beta^{c} a_{2}+\frac{\beta^{c}\left(a_{1}-h_{1}-\delta E(a)\right)+\delta w}{1+\delta}
$$

3. (Capacity regime) If $\beta^{c}\left(a_{1}-h_{1}+\bar{h}\right)<\delta \beta^{c}(E(a)-\bar{h})-\delta w$, then

$$
p_{1}^{c}=\beta^{c}\left(a_{1}-h_{1}+\bar{h}\right), \quad p_{2}^{c}=\beta^{c}\left(a_{2}-\bar{h}\right)
$$

Proof: See appendix.||

\subsection{Monopolistic production, competitive speculation}

The objective of the monopoly is to maximize its expected total profit taking into account the impact of its choice on future inventories. The Bellman equation for the monopolist's problem is

$$
V_{1}^{m}\left(a_{1}, h_{1}\right)=\max _{p_{1}}\left\{p_{1} D_{1}\left(p_{1} ; a_{1}, h_{1}\right)-\frac{c}{2}\left(D_{1}\left(p_{1} ; a_{1}, h_{1}\right)\right)^{2}+\delta E_{1} V_{2}^{m}\left(a_{2}, h_{2}\right)\right\}
$$

The price and quantity sold in second period result from the maximization of the second period monopoly profit $\pi_{2}^{m}=\left(a_{2}-h_{2}-p_{2}\right) p_{2}-c\left(a_{2}-h_{2}-p_{2}\right)^{2} / 2$ with respect to $p_{2}$, giving

$$
p_{2}^{m}=\beta^{m}\left(a_{2}-h_{2}\right)
$$

where $\beta^{m}=(1+c) /(2+c)$. Using the definition of $\beta^{m}$, we can solve for $c=\frac{2 \beta^{m}-1}{1-\beta^{m}}$, and write

$$
V_{2}^{m}\left(a_{2}, h_{2}\right)=\frac{\left(1-\beta^{m}\right)}{2}\left(a_{2}-h_{2}\right)^{2} .
$$

Given (34), we have $g^{m}\left(h_{2}\right) \equiv E_{1}\left(p_{2} \mid h_{2}\right)=\beta^{m}\left(E(a)-h_{2}\right)$, from which we derive the price thresholds (12) and (13):

$$
p_{\ell}^{m}=\delta g^{m}(\bar{h})-\delta w=\delta \beta^{m}(E(a)-\bar{h})-\delta w
$$


and

$$
p_{u}^{m}=\delta g^{m}(0)-\delta w=\delta \beta^{m} E(a)-\delta w .
$$

For $p_{1} \in\left[p_{\ell}^{m}, p_{u}^{m}\right]$ speculative sales must be sufficient to ensure that $p_{1}=\delta g^{m}\left(h_{2}\right)-\delta w$. Using the above expression for $g^{m}\left(h_{2}\right)$ and $h_{2}=h_{1}-x_{1}$ we have

$$
x_{1}=h_{1}-E(a)+\left(w+\frac{p_{1}}{\delta}\right) / \beta^{m} .
$$

We can now write the residual demand faced by the monopolist:

$$
D_{1}\left(p_{1} ; a_{1}, h_{1}\right)= \begin{cases}a_{1}-h_{1}-p_{1}+\bar{h} & \text { if } p_{1}<p_{l}^{m} \\ a_{1}-h_{1}-p_{1}+E(a)-\frac{w}{\beta^{m}}-\frac{p_{1}}{\delta \beta^{m}} & \text { if } p_{1} \in\left[p_{l}^{m}, p_{u}^{m}\right] \\ a_{1}-h_{1}-p_{1} & \text { if } p_{1}>p_{u}^{m} .\end{cases}
$$

It will be useful to introduce notation that represents the monopolists payoff as a function of $p_{1}$ for the different regimes. For the stock-out regime we have

$$
\Pi_{1}^{1}\left(p_{1}\right) \equiv p_{1}\left(a_{1}-h_{1}-p_{1}\right)-\frac{c}{2}\left(a_{1}-h_{1}-p_{1}\right)^{2}+\delta \frac{1-\beta^{m}}{2} E_{1}\left[a_{2}^{2}\right] .
$$

For the smoothing regime we have

$$
\begin{aligned}
\Pi_{1}^{2}\left(p_{1}\right) \equiv & p_{1}\left(a_{1}-h_{1}-p_{1}+E(a)-\frac{w}{\beta^{m}}-\frac{p_{1}}{\delta \beta^{m}}\right) \\
& -\frac{c}{2}\left(a_{1}-h_{1}-p_{1}+E(a)-\frac{w}{\beta^{m}}-\frac{p_{1}}{\delta \beta^{m}}\right)^{2} \\
& +\delta \frac{1-\beta^{m}}{2} E_{1}\left[\left(a_{2}-E(a)+\frac{w}{\beta^{m}}+\frac{p_{1}}{\delta \beta^{m}}\right)^{2}\right] .
\end{aligned}
$$

Finally, for the capacity regime we have

$$
\Pi_{1}^{3}\left(p_{1}\right) \equiv p_{1}\left(a_{1}-h_{1}-p_{1}+\bar{h}\right)-\frac{c}{2}\left(a_{1}-h_{1}+\bar{h}-p_{1}\right)^{2}+\delta \frac{1-\beta^{m}}{2} E_{1}\left[\left(a_{2}-\bar{h}\right)^{2}\right] .
$$

The first period value function for the monopolist can now be expressed as

$$
V_{1}^{m}\left(a_{1}, h_{1}\right)=\max _{p_{1}} \begin{cases}\Pi_{1}^{3}\left(p_{1}\right) & \text { if } p_{1}<p_{\ell} \\ \Pi_{1}^{2}\left(p_{1}\right) & \text { if } p_{1} \in\left[p_{l}^{m}, p_{u}^{m}\right] \\ \Pi_{1}^{1}\left(p_{1}\right) & \text { if } p_{1}>p_{u}^{m}\end{cases}
$$

We present the solution to this optimization problem in Proposition 2 below, but first note that the objective function for the maximization problem in (43) is continuous but 
non-differentiable at prices $p_{\ell}$ and $p_{u}$. It is important to note that both the demand, (39), and $h_{2}$ (and hence second period profit) exhibit kinks at these prices. We plot marginal total profit in Figure 1, illustrating the discontinuities in the monopolist's marginal payoff. The height of the lines in Figure 1 vary with $a_{1}-h_{1}$ and so the equilibrium price will be determined by which line segment intersects the horizontal axis. The situation depicted in Figure 1 has a high price chosen resulting in a stock-out. The downward jump in marginal payoff at $p_{u}$ implies that there is a set of $a_{1}$ and $h_{1}$ values for which the monopolist charges the same price, $p_{u}$. The upward jump at $p_{\ell}$ means that there can be two local maxima (when the horizontal axis cuts across that jump), however, we show that the global maximum in this case occurs at the price in the smoothing regime.

Figure 1: Marginal Profit

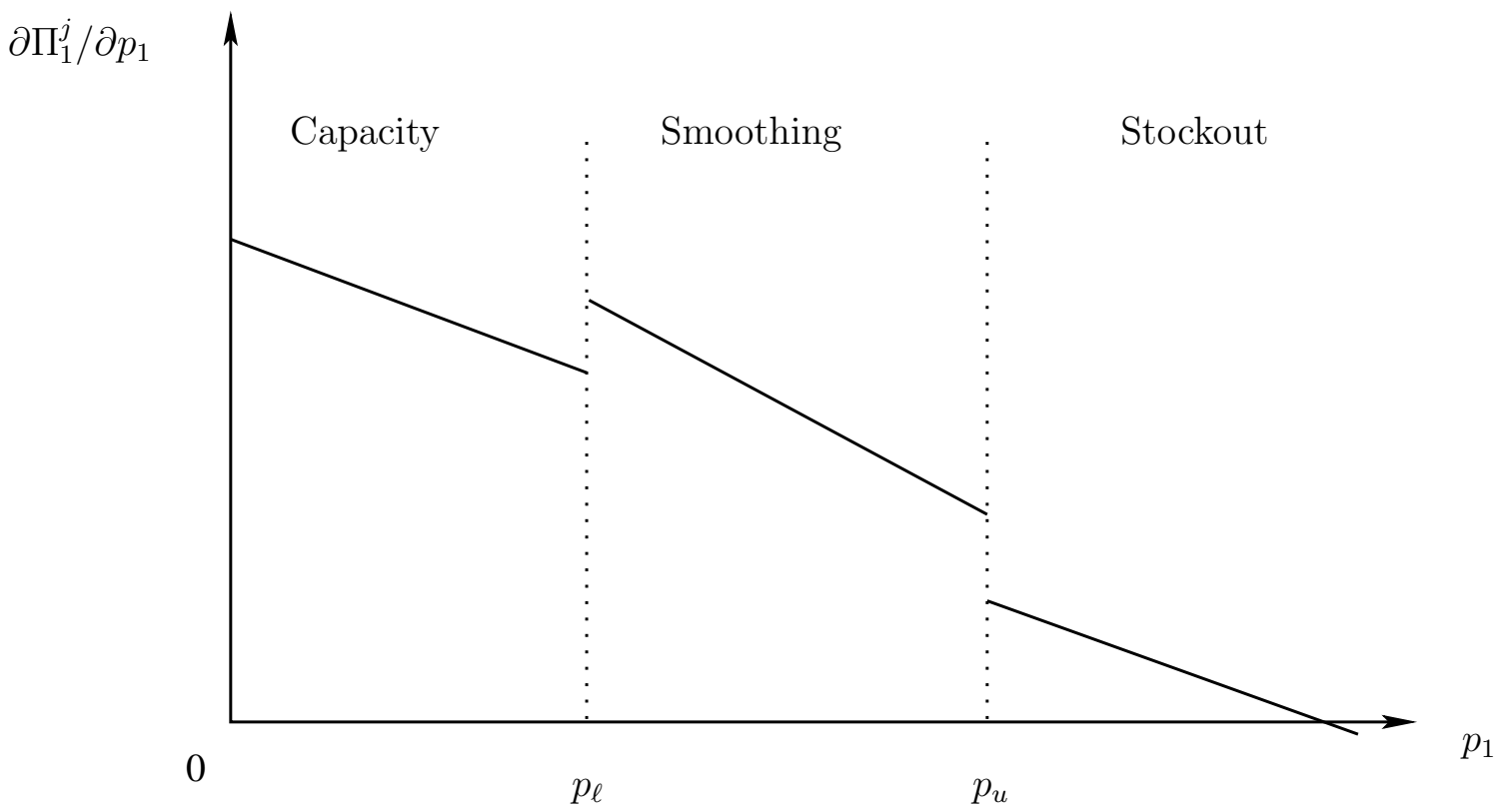

These statements are presented more formally in Proposition 2, but first we introduce an additional assumption that speculators' capacity is not too small, which ensures that there is a non-negligible smoothing region:

\section{Assumption 2}

$$
\frac{\delta\left(1-\beta^{m}\right)^{2} w}{\beta^{m}\left(\delta\left(\beta^{m}\right)^{2}+2 \beta^{m}-1\right)} \leq(1+\delta) \bar{h}
$$

We can now characterize the equilibrium under monopolistic production: 
Proposition 2 Under Assumptions 1 and 2, and for a given $\left(a_{1}, h_{1}\right)$, the equilibrium under monopoly is characterized as follows:

1. (Stock-out) If $a_{1}-h_{1}-\delta E\left[a_{2}\right]+\delta w / \beta^{m} \geq 0$ then

$$
p_{1}^{*}=\beta^{m}\left(a_{1}-h_{1}\right), \text { and } p_{2}^{*}=\beta^{m} a_{2}
$$

2. (Stock-out) If $a_{1}-h_{1}-\delta E\left[a_{2}\right]+\delta w / \beta^{m}<0 \leq a_{1}-h_{1}-\delta E\left[a_{2}\right]+K w$ then

$$
p_{1}^{*}=p_{u}^{m}, \text { and } p_{2}^{*}=\beta^{m} a_{2}
$$

3. (Smoothing) If $a_{1}-h_{1}-\delta E\left[a_{2}\right]+K w<0 \leq a_{1}-h_{1}-\delta E\left[a_{2}\right]+(1+\delta) \bar{h}+K w$ then

$$
p_{1}^{*}=\frac{\delta \beta^{m}}{1+\delta}\left(a_{1}-h_{1}+E(a)\right)+\frac{\delta\left(1-2 \beta^{m}\right) w}{\delta \beta^{m^{2}}+2 \beta^{m}-1}
$$

and

$$
p_{2}^{*}=\beta^{m}\left(a_{2}+\frac{a_{1}-h_{1}}{1+\delta}-\frac{\delta}{1+\delta} E(a)\right)+\frac{\delta \beta^{m 2} w}{\delta\left(\beta^{m}\right)^{2}+2 \beta^{m}-1}
$$

4. (Capacity) Finally, if $a_{1}-h_{1}-\delta E\left[a_{2}\right]+(1+\delta) \bar{h}+K w<0$ then

$$
p_{1}^{*}=\beta^{m}\left(a_{1}-h_{1}+\bar{h}\right) \text {, and } p_{2}^{*}=\beta^{m}\left(a_{2}-\bar{h}\right) .
$$

where $K \equiv \frac{\delta \beta^{m}(1+\delta)}{\delta \beta^{m}+2 \beta^{m}-1}$.

Proof: See appendix.\|

\subsection{Comparison between perfect competition and monopoly}

The likelihood of the different price regimes as a function of the state $\left(a_{1}, h_{1}\right)$ varies by market structure. To investigate this issue, let us rank the bounds of all the regions presented in propositions 1 and 2. From the proofs of these two propositions, we know that belonging to each of the regions depends on the comparison between $a_{1}-h_{1}-\delta E(a)$ and a function of $c, \delta, w$ and $\bar{h}$. Ranking the different bounds is straightforward: we can summarize the different price regimes in perfect competition and in monopoly by Figure 2 . Under monopoly production, four different regimes are possible, while there are only 3 regimes under perfect competition. The areas labeled "Capacity" in Figure 2 are the sets of values of $\left(a_{1}, h_{1}\right)$ such that speculators store the product up to their capacity. Given initial inventories $h_{1}$, this regime occurs when $a_{1}$ is sufficiently lower than $E(a)$. Note that the area of this region is larger under monopoly production than it is under competitive production. Hence, given $h_{1}$, the likelihood of being in a capacity regime is larger under a monopoly than under perfect competition (when it has non-zero probability). 
Figure 2: Regimes: Perfect Competition and Monopoly
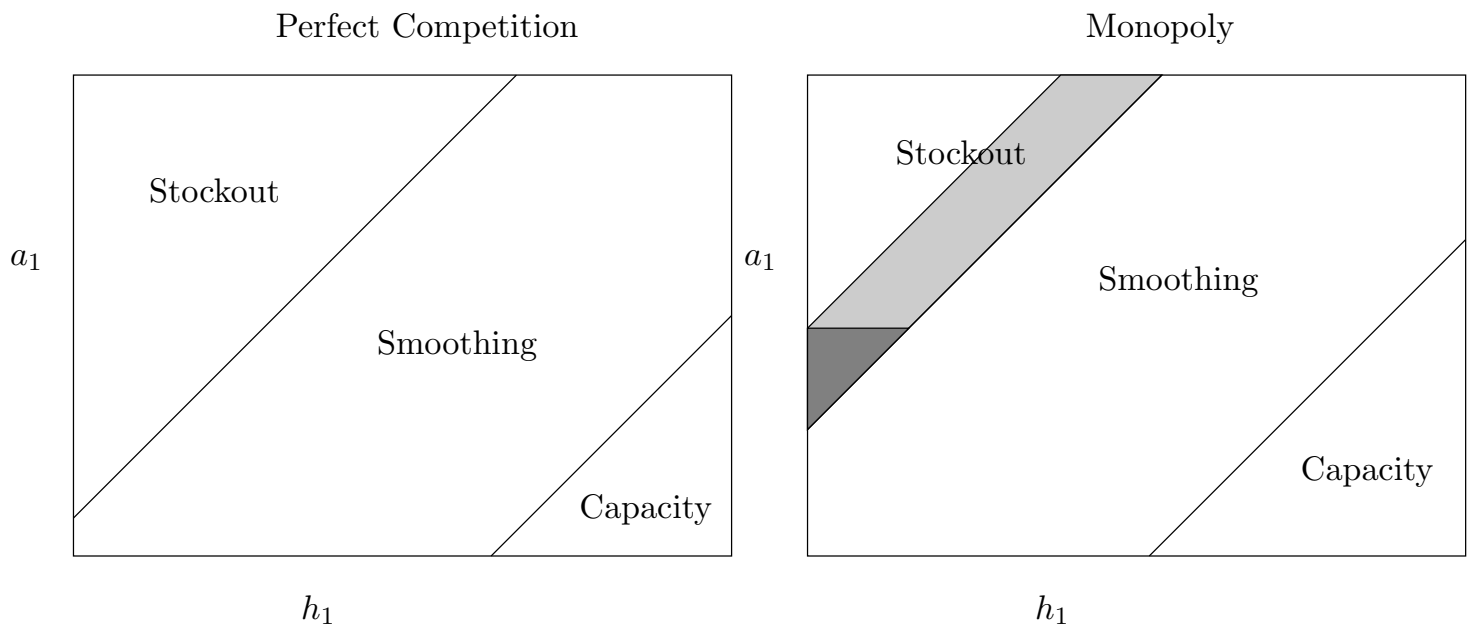

The central "Smoothing" areas of Figure 2 show the values of $\left(a_{1}, h_{1}\right)$ such that the market is in a smoothing regime. This occurs for intermediate/small values of $a_{1}$ compared to $E(a)$. The areas of the smoothing regions is the same under both market structures, however, smoothing occurs for higher values of $a_{1}$ (given $h_{1}$ ) under a monopoly compared to perfect competition.

The "Stock-out" regions of Figure 2 show the values of $\left(a_{1}, h_{1}\right)$ such that speculators sell all their stocks. The area where stock-outs occur is smaller under monopoly than under perfect competition and occurs for higher values of first period demand. An interesting sub-region of the smoothing area is the one in which the monopoly sets the price exactly at the stock-out threshold $\left(p_{u}^{m}\right)$. This is the shaded region in Figure 2. For these values of first period demand and initial inventories, the monopoly keeps price at $p_{u}^{m}$ even as $a_{1}$ falls in order to ensure no stocks are carried into the second period.

It is interesting to compare the level of prices charged by a monopoly which faces speculation with the level of prices charged by a static monopoly, which is equal to $\beta^{m} a_{t}$ in any period. Because of the speculative activity, prices are often higher compared to the static monopoly in one period and lower in the other. There is however an interesting case: when a stock-out occurs at price $p_{\ell}$, (the shaded area in Figure 2) the price may be higher than what a static monopoly would charge in the first period, and equal to the static monopoly price in second period (case 2 of Proposition 2). This implies that the average price is increased by speculative activity. The region where this occurs is shaded more darkly in Figure 2.

So far we have dealt with the case in which $h_{1}$ is exogenous. This does not allow us to consider the possibility that inventory levels may differ across market structures. In order 
to address this possibility, we now turn to the analysis of the model with an infinite time horizon.

\section{$5 \quad$ Infinite horizon analysis}

We now turn to an analysis of the model in an infinite horizon setting. This will relax two limitations of the two-period model. First, the equilibrium price in the previous section was a function of initial stocks, $h_{1}$. Since there is no way to distinguish the different levels of stocks expected to be held under monopoly versus perfect competition in the two-period setting, we were not able to fully characterize the price distribution. Second, in the twoperiod model speculators sell their stocks in the second period as long as price is positive. This likely exaggerates the desire of the monopolist to limit storage.

It is well known that there is no closed-form solution to the infinite horizon storage problem, even in the case of competitive production (Williams and Wright [14]). Consequently, the analysis of this section proceeds by numerical solutions to the problem under the alternative conditions of competitive and monopolistic production. We will describe the solution method that we use for the two market structures next. Following that we provide a comparison of the equilibrium under the two market structures for a particular set of values for the parameters.

\subsection{Monopoly production and competitive storage}

In the model with monopoly production, there are two unknown functions that need to be determined in order to solve the problem: the monopolist's value function, $V^{m}\left(a_{t}, h_{t}\right)$, and speculators' price expectations, $E_{t}\left[p_{t+1}\right] \equiv g\left(h_{t+1}\right)$. Since the value function described in (26) is not expected to be smooth, we choose instead to approximate the expectation of next period's value function, $E_{t}\left[V^{m}\left(a_{t+1}, h_{t+1}\right)\right] \equiv \tilde{V}^{m}\left(h_{t+1}\right)$. This has the added advantage that the function being approximated depends on only one variable.

We will proceed by using the collocation $\operatorname{method}^{3}$ to compute approximate solutions for $g\left(h_{+}\right)$and $\tilde{V}^{m}\left(h_{+}\right)$. In particular, we use

$$
\tilde{V}^{m}\left(h_{+}\right) \approx \sum_{i=0}^{n} c_{i} \phi_{i}\left(h_{+}\right)
$$

where $c_{i}$ are coefficients and the $\phi_{i}()$ are known basis functions. We use Chebyshev polynomials for the $\phi_{i}()$ functions in what follows. Similarly

$$
g\left(h_{+}\right) \approx \sum_{i=0}^{n^{\prime}} d_{i} \phi_{i}\left(h_{+}\right)
$$

\footnotetext{
${ }^{3}$ See Judd [6], Chapter 11.
} 
The collocation method forces these approximations to be exact at the $n$ and $n^{\prime}$ collocation nodes.

\subsubsection{Numerical Algorithm}

Three numerical routines are required to solve the model: a routine to compute Chebyshev approximations, a routine to integrate the price and value functions, and a routine to solve the fixed point problem in the smoothing region. We use the gsl_cheb, gsl_integrate_qag, and gsl_root_fsolver_brent routines from the GNU Scientific Library ${ }^{4}$ for these tasks.

The algorithm is

Step 0. Choose degrees of approximation, $n$ and $n^{\prime}$. Initialize starting values $d^{0}, c^{0}$. These are chosen as Chebyshev approximations to decreasing linear functions since both $g\left(h_{t+1}\right)$ and $\tilde{V}^{m}\left(h_{t+1}\right)$ are expected to be decreasing.

Step 1. Update the price expectations equation by finding $d^{1}$ such that

$$
\sum_{i=0}^{n^{\prime}} d_{i}^{1} \phi_{i}\left(h_{+i}^{\prime}\right)=\int p\left(a, h_{+i}^{\prime}\right) \theta(a) d a
$$

where $\theta(a)$ is the density of $a_{t}$. Here the new $d^{1}$ are found by forcing this to hold at the $n^{\prime}$ collocation nodes and the price is evaluated using the approximations defined by $d^{0}$ and $c^{0}$. The price function on the right-hand side is found by computing the feasible choice for the monopolist that yields the highest value and using the resulting price. In other words, given the current approximation, we solve (18), (20), and (25) and the corresponding value for each to get the optimal production and price choice. This optimal price is used in the numerical integration of the right-side of (46).

Step 2. Update the value function expectation by $c^{1}$ such that

$$
\sum_{i=0}^{n} c_{i}^{1} \phi_{i}\left(h_{+}\right)=\int V^{m}\left(a, h_{+}\right) \theta(a) d a
$$

Here the new $c^{1}$ are found by forcing this to hold at the $n$ collocation nodes and value function is evaluated using the approximations defined by $d^{0}$ and $c^{0}$. The value function on the right-hand side is found by computing the feasible choice for the monopolist that yields the highest value. In the same manner as for the previous step, we solve (18), (20), and (25) and use the corresponding value for each in (26) to get the values used in the right-side of (47).

Step 3. Stop if $\left\|d^{1}-d^{0}\right\|$ and $\left\|c^{1}-c^{0}\right\|$ are smaller than the convergence criterion ${ }^{5}$. Otherwise set $d^{0}=d^{1}, c^{0}=c^{1}$, and return to Step 1 .

\footnotetext{
${ }^{4}$ Galassi [5]

${ }^{5}$ We use 1.0E-10.
} 


\subsection{Competitive production and storage}

The model with competitive production and storage is the benchmark case that has seen substantial analysis in previous work (for example see Williams and Wright [14]). The only difference between our model with competitive production and the standard treatment is the addition of a capacity constraint ${ }^{6}$

Given the quadratic production costs we are using, competitive supply is simply $p_{t} / c$. Stock-outs occur if $p_{t}>\delta\left(E\left[p_{t+1}\right]-w\right)$, which, using the demand function, reduces to $a_{t}>h_{t}+\delta\left(E\left[p_{t+1}\right]-w\right)(1+c) / c$. Similarly, storage to capacity occurs if $a_{t}<h_{t}-\bar{h}+$ $\delta\left(E\left[p_{t+1}\right]-w\right)(1+c) / c$. Hence equilibrium price for any $a_{t}, h_{t}$ combination is

$$
p_{t}= \begin{cases}\left(a_{t}-h_{t}+\bar{h}\right) c /(1+c) & \text { if } a_{t}<h_{t}+\left(\delta\left(E\left[p_{t+1}\right]-w\right)\right)(1+c) / c \\ \left(a_{t}-h_{t}\right) c /(1+c) & \text { if } a_{t}>h_{t}-\bar{h}+\left(\delta\left(E\left[p_{t+1}\right]-w\right)\right)(1+c) / c \\ \delta E_{t}\left[p_{t+1}\right]-\delta w & \text { otherwise }\end{cases}
$$

This problem is simpler than the one in the case of monopoly production since there is only one unknown function to approximate. We proceed by approximating $E\left[p_{t+1}\right]$ with a Chebyshev polynomial $\sum_{i=0}^{n} d_{i} \phi_{i}(x)$ and finding the $d_{i}$ that result in a close approximation to the expectation of (48) when evaluated at period $t+1$. The main difficulty is to find the value of $h_{t+1}$ to use in the last case of (48). In particular, since $p_{t}=\delta E_{t}\left[p_{t+1} \mid h_{t+1}\right]-\delta w$ in this case, we must have

$$
a_{t}-h_{t}+h_{t+1}-\left(\delta \sum_{i=0}^{n} d_{i} \phi_{i}\left(h_{t+1}\right)-\delta w\right) / c=\delta \sum_{i=0}^{n} d_{i} \phi_{i}\left(h_{t+1}\right)-\delta w
$$

which we solve with the root-finding algorithm. The solution algorithm is similar to the one used in the monopoly case, but with Step 2 omitted.

\subsection{Example}

We present the solution to the problem for parameter values of $\delta=0.95, c=0.5, w=$ $0.1, \bar{h}=1$. The demand intercept is assumed to be normally distributed with $E\left[a_{t}\right]=5$ and variance of 1.0. With these parameters, the average price charged by a static monopoly is equal to 3. The orders of the Chebyshev polynomials are $n=n^{\prime}=8$ for the expected price and expected value functions in the monopoly case and $n=6$ in the competitive case. $^{7}$ The largest residual error for both approximations is of the order E(-4).

Figure 3 plots the equilibrium price function for both market structures: $p_{t}$ versus $a_{t}$ and $h_{t}$. The upper surface is the monopolist's price function, while the lower surface is that for the perfectly competitive market. The relatively flat portion of each plot is where

\footnotetext{
${ }^{6}$ Miranda and Fackler[8] apply a constraint in their example of this problem.

${ }^{7}$ The expected price and expected value functions are much smoother than the non-differentiable price and value functions, which permits a relatively low degree approximation.
} 
Figure 3: Equilibrium price: Monopoly (top) and Competitive (bottom)

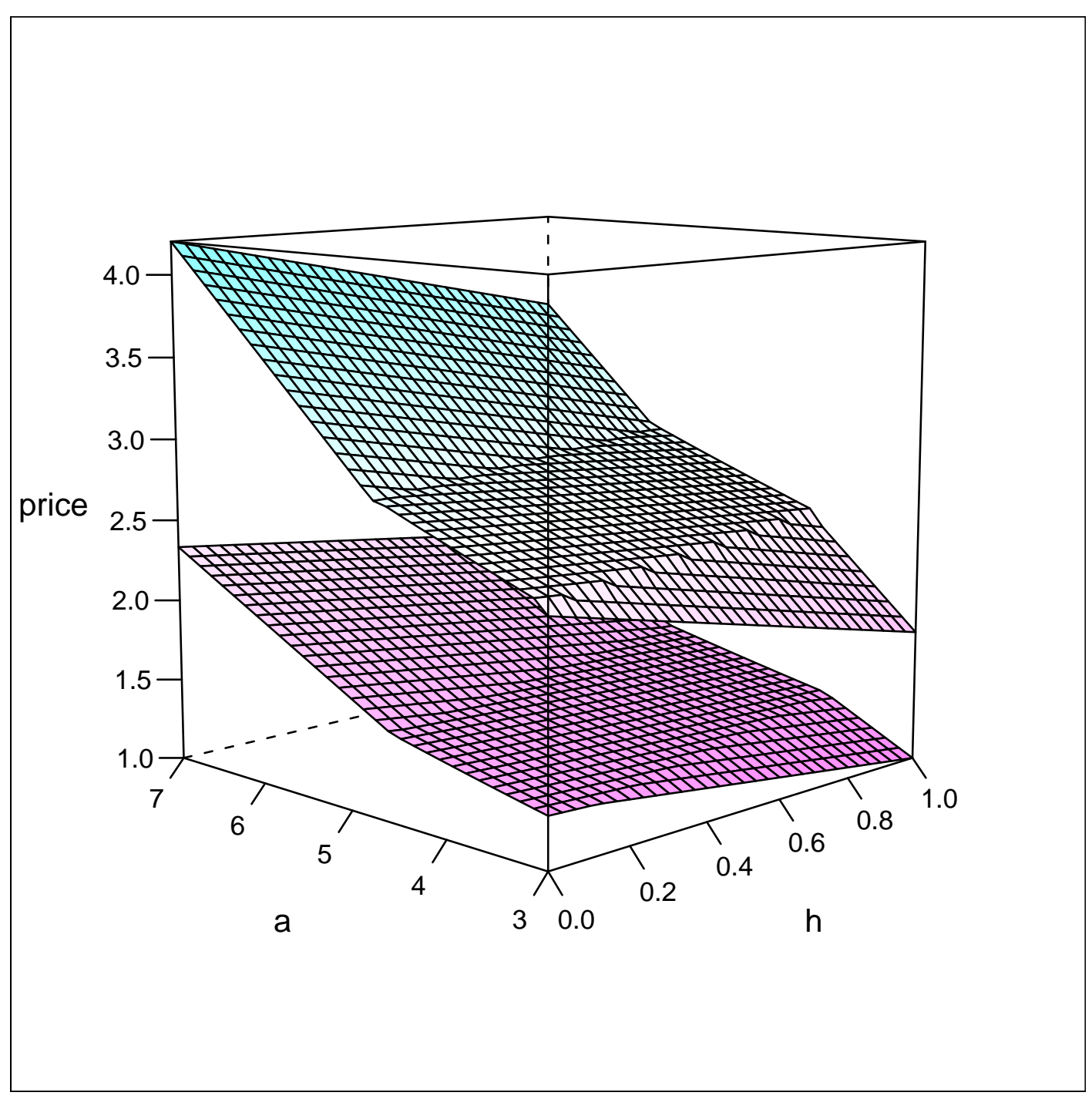


smoothing occurs. Kinks occur at the boundaries to the smoothing region. We see that as was the case in the two-period model, for a given level of inventories, the threshold demand shock at which stock-outs occur is higher for the monopolist than for the perfectly competitive market. This corroborates our findings on the two periods case in the sense that a stock-out is more likely in a perfectly competitive market than a monopoly at a given level of inventories. ${ }^{8}$ One final point to make about Figure 3 is that the monopoly price function has a steeper slope as $a_{t}$ varies than the competitive one does for any value of $h_{t}$. This implies a higher price variance under monopoly, and consequently a higher return to storage so we would expect to see more inventories carried under monopoly production.

Figure 3 shows price for a given state. However, it is likely that the distribution of inventories will differ under the different market structures. This implies that to know what the actual differences in the price distribution will be, we need to compute the distribution of inventories under the different market structures. In order to see the effects of market structure on the equilibrium distributions of price and inventories, we generate series for $a_{t}$ that are 1000 periods long, computing prices and inventories levels for each period, beginning with $h_{0}=0$. We construct 500 such samples to generate averages over the 500 samples of some statistics of interest, which are presented in the first two rows of Table 1. We also present the static case $(\bar{h}=0)$ as a benchmark along with values for $\bar{h}=3.0$ which is a large enough capacity for the capacity constraint to be effectively non-binding. Not surprisingly, the monopoly price is generally higher than that of the competitive industry. Also, prices under monopoly are significantly more volatile than is efficient. Monopoly prices are also slightly more skewed and autocorrelated than competitive ones. The higher price volatility results in storers holding more inventories under a monopolist, which combined with the lower output results in a substantially higher inventory/production ratio. Also, stock-outs occur less frequently and capacity regimes occur more frequently under the monopolist.

The variance of price under monopoly remains higher than that under perfect competition. This occurs in spite of the fact that speculators carry more inventory when production is done by a monopolist. The inventory-production ratio under monopoly production is double what it is under competitive production. The effect of these larger inventory holdings are seen when we compare the reduction in price variance due to storage under the two market structures. Moving from no speculative capacity to $\bar{h}=1.0$ results in a $27 \%$ reduction in price variance under competitive production and a $39 \%$ reduction under monopoly production. Hence, speculators have a more dramatic effect on volatility in the monopoly case.

Skewness and serial correlation are both higher under monopoly than perfect competition. This is interesting in light of the empirical work examining the ability of the competitive storage model to fit these moments of the price distribution. In particular

\footnotetext{
${ }^{8}$ Of course, the equilibrium level of inventories held under the different market structures will not necessarily be the same.
} 
Table 1: Simulated statistics

E[p] $\operatorname{Var}[\mathrm{p}] \quad$ Skew $[\mathrm{p}] \quad$ Cor $[\mathrm{p}] \quad \mathrm{E}[\mathrm{h}] \quad \mathrm{E}[\mathrm{h} / \mathrm{q}] \quad$ Stock-out Capacity

$\begin{array}{lllllllll}\bar{h}=0 & & & & & & & & \\ \text { P.C. } & 1.67 & 0.11 & 0.00 & 0.00 & & & & \\ \text { Monopoly } & 3.00 & 0.36 & 0.00 & 0.00 & & & & \\ \bar{h}=1 & & & & & & & & \\ \text { P.C. } & 1.67 & 0.08 & 0.62 & 0.17 & 0.16 & 0.05 & 0.60 & 0.03 \\ \text { Monopoly } & 3.02 & 0.22 & 0.65 & 0.19 & 0.20 & 0.10 & 0.55 & 0.05 \\ \bar{h}=3.0 & & & & & & & & \\ \text { P.C. } & 1.67 & 0.07 & 0.79 & 0.18 & 0.18 & 0.06 & 0.59 & 0.00 \\ \text { Monopoly } & 3.03 & 0.20 & 1.01 & 0.20 & 0.24 & 0.12 & 0.53 & 0.00\end{array}$

Deaton and Laroque $[2,3]$ find that prices exhibit much higher degrees of serial correlation than can be attributed to the competitive storage model. This results here suggest that market power might be another contributing factor to examine.

The final two columns of Table 1, labelled "Stock-out" and "Capacity" report the proportion of periods spent in that regime. We find that, as suggested by the two-period model, stock-outs occur less frequently under monopoly than under perfect competition. There are two effects causing this difference. First, the set of values of $\left(a_{t}, h_{t}\right)$ for which a stock-out occurs is smaller under monopoly (as was the case in Figure 2). Second, speculators hold more inventories on average under monopoly production. This reduces the likelihood of a stock-out as well. Also consistent with the two-period analysis is the result that capacity regimes are experienced more frequently under monopoly.

Finally, unlike in the model of Thille [13], we find effects of storage on the level of price. Comparing the $\bar{h}=0$ and $\bar{h}>1.0$ results, we see that their is a slightly higher average price when the monopolist faces speculators than when it does not. Like in the two-period model, there are circumstances in which the monopolist chooses to set the price exactly equal to the stock-out threshold and does so for a range of values of the state variables. This failure to reduce price smoothly with the state results in slightly higher average price when speculators are present. In order to see this more clearly, we plot histograms of prices 
from a single long simulation (100,000 observations) in Figure 4. The first column of the figure plots histograms for the parameters discussed above. This figure highlights that the mass point in prices that was found in the two-period model also occurs in the infinite horizon solution. Under monopoly, the price equals the upper bound $\left(p_{u}\right)$ about $2.6 \%$ of the time, while under perfect competition it essentially never occurs. Hence the qualitative difference in equilibrium prices that occurred in the two-period model continues to exist in the long-horizon case. The second column plots histograms for a larger value of the storage cost parameter, which presents a clearer view of the mass point that occurs under monopoly production. As storage costs become larger, the qualitative differences in the price distribution under the different market structures become accentuated.

To give some idea of the robustness of these results, Figures 5 and 6 plot price variance and inventory levels for a range of values of $\bar{h}$. The maximum value of $\bar{h}=3.0$ represents an effectively non-binding constraint for these parameter values so those values are representative of the model without a capacity constraint. Descriptive statistics for $\bar{h}=3.0$ are provided in the last two rows of Table 1. The qualitative results are robust to variations in $\bar{h}$. The difference between price variance under monopoly versus perfect competition is somewhat reduced as capacity increases, but monopoly price variance remains substantially higher even when capacity no longer binds. Furthermore, Figure 6 suggests that the constraint has more effect on storage under a monopoly, as storers increase average stocks held more quickly as the constraint is relaxed. This later result is again due to the fact that prices are more volatile under the monopoly so speculators have a stronger desire to increase inventories and hence, more likely to be capacity constrained when $\bar{h}$ is small.

\subsection{The returns to speculation}

Since price volatility differs across market structures, it is natural to ask what the effect of free entry in speculation would be. In particular, we can examine the payoff to speculators (in aggregate) for a given storage capacity. Since prices are more volatile under monopoly production, we would expect speculative returns to be higher for a given level of capacity, and consequently more capacity to appear in a long-run equilibrium.

Rather than finding the speculators' value function explicitly, we compute the discounted present value of the returns to speculators (equation (4)) over the 1000 periods of the simulated series ${ }^{9}$ and average over our 500 samples. Speculative returns under the two market structures are plotted in Figure 7. Due to the higher price volatility speculation is substantially more profitable under monopoly production. If one were to superimpose a plot of the cost of capacity on this figure (say due to the opportunity cost of space for storage), then the intersection of the two would depict the long-run level of storage capacity. Clearly, for any cost of capacity low enough to allow speculation, a free entry equilibrium

\footnotetext{
${ }^{9}$ Given the discount factor we use, the truncation to 1000 periods has no discernible impact on the calculation of (4)
} 
Figure 4: Histogram of price
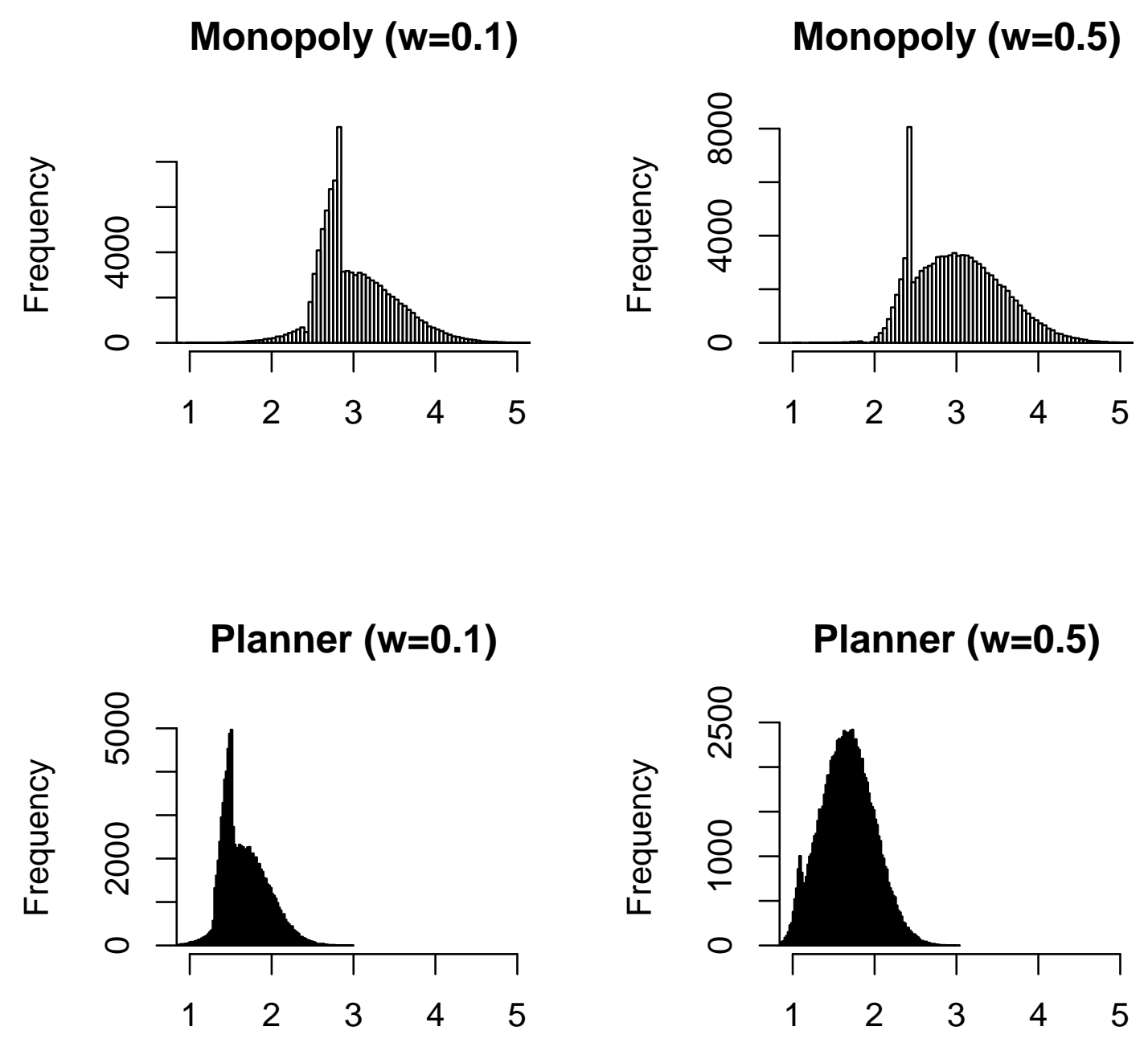
Figure 5: Price variance: Competitive vs. Monopoly production

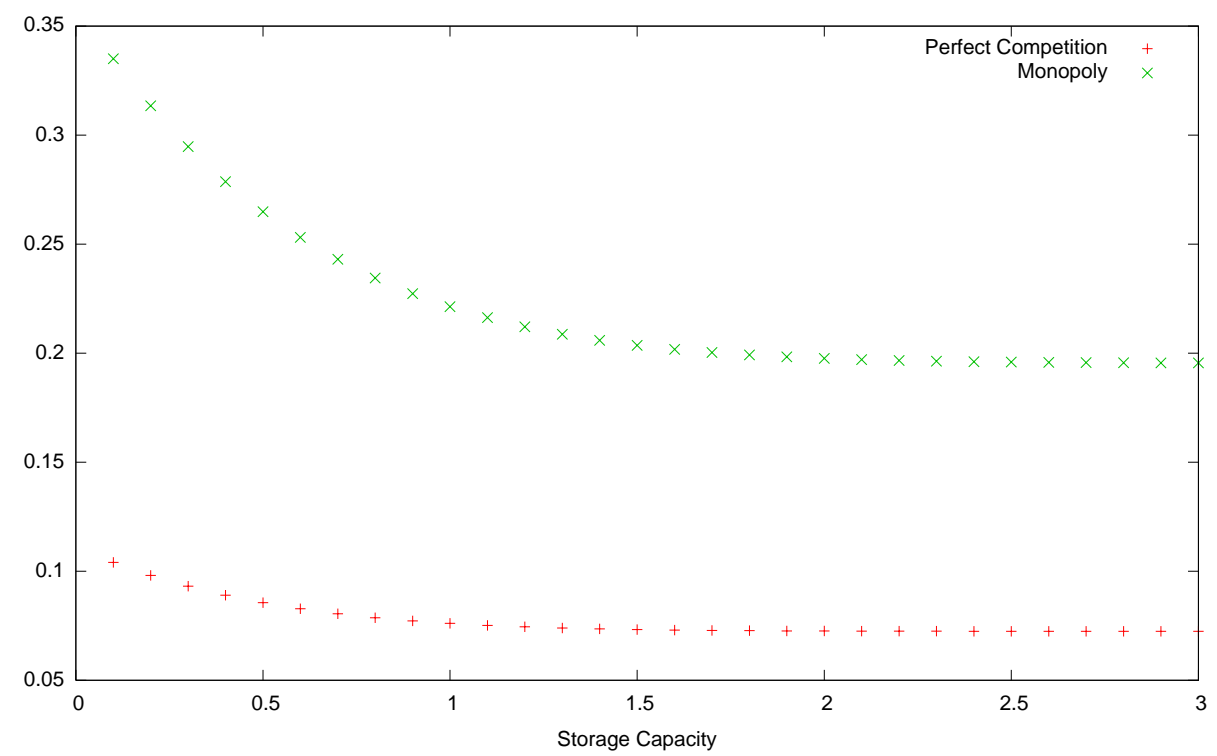

Figure 6: Inventory levels: Competitive vs. Monopoly production

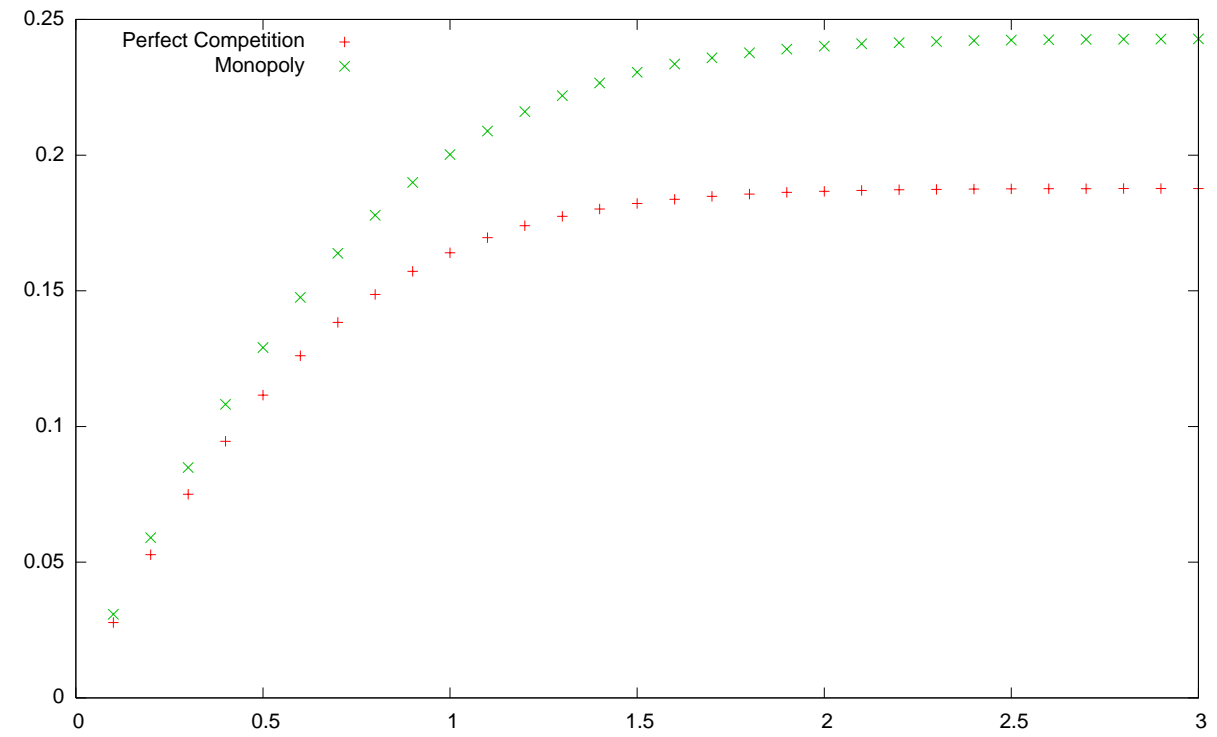


Figure 7: Returns to speculation: Competitive vs. Monopoly production

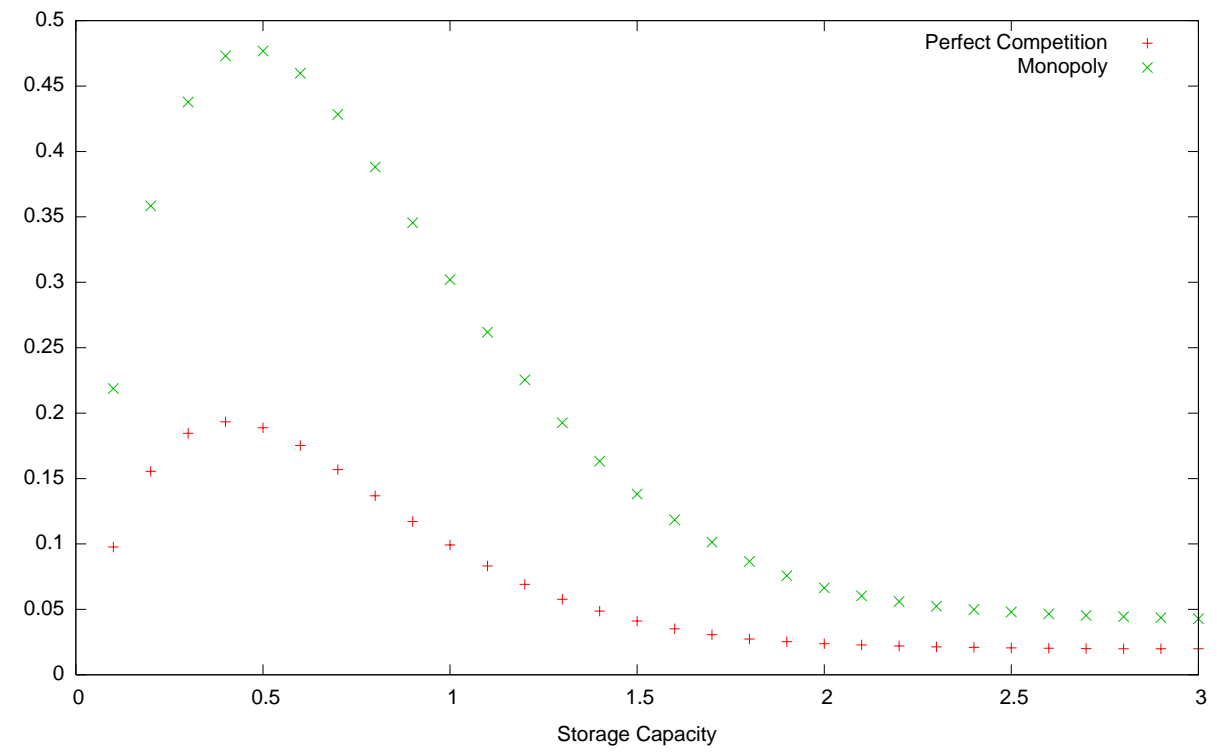

will result in more storage capacity under monopoly production than would occur under perfectly competitive production.

We can get some idea of the difference in long-run equilibrium between the monopoly and the perfectly competitive markets by normalizing capacity in the competitive industry to $\bar{h}=1.0$. From Figure 7 , if capacity costs were linear and generated $\bar{h}=1.0$ for competitive production, zero-profit capacity for the case of monopoly production would occur at approximately $\bar{h}=1.5$. Facing this capacity, equilibrium price variance under the monopolist would be 0.20 . Comparing this to the variance in the case of $\bar{h}=1.0$, entry of speculative capacity does narrow the gap in price variance between the two market structures, however price remains significantly more volatile under monopoly, even with the larger amount of inventories being held. In addition, the higher level of inventories held does generate more serial correlation in the monopoly case $(0.20$ in the case of $\bar{h}=1.5))$, which is interesting given that Deaton and Laroque $[3,2]$ find that the model with competitive supply does not generate as much serial correlation as is found in the data. However, the increase in serial correlation in prices is not so large as to fully explain the extent of serial correlation that they found in the data.

\section{Conclusion}

This paper represents a first attempt to analyze the effectiveness of competitive storage in the presence of imperfectly competitive production of a commodity. Our two-period 
model showed that stock-outs occur less frequently and that storage to capacity occurs more frequently under monopoly than under perfect competition. We confirmed this result using numerical solutions to the infinite horizon version of the model. In addition, even though the long-run equilibrium has more inventories carried under monopoly production, this extra storage is not enough to remove the significant difference in price volatility under the two market structures.

The fact that competitive storage introduces kinks into the monopolist's residual demand curve results in a mass point in the price distribution. There exists a non-trivial range of demand states over which the monopolist wishes to hold price constant at the level that just induces a stock-out. The advantage of this is that there are no stocks to compete with the monopolist's production in the next period. This effect is completely absent under perfectly competitive production. 


\section{Appendix}

\section{A Proof of proposition 1}

Equilibrium is given by intersection of $D_{1}\left(p_{1}, h_{1}\right)$ and $S_{1}\left(p_{1}\right)$. Two cases are trivial: the "capacity" regime and the "stock-out" regime. In the first case, demand is given by $D_{1}\left(p_{1}, h_{1}\right)=a_{1}-p_{1}-h_{1}+\bar{h}$, and the intersection with the competitive supply gives a market price equal to $p_{1}^{c}=\beta^{c}\left(a_{1}-h_{1}+\bar{h}\right)$. Inventories carried forward are $h_{2}=\bar{h}$, and the competitive price in equilibrium must be such that speculators indeed find profitable to pile stocks up to their storage capacity, that is $p_{1}^{c}$ must be strictly lower than $p_{l}^{c}$, giving a condition on first period demand:

$$
\beta^{c}\left(a_{1}-h_{1}+\bar{h}\right)<\delta \beta^{c}(E(a)-\bar{h})-\delta w,
$$

or

$$
a_{1}<\delta E(a)+h_{1}-(1+\delta) \bar{h}-\delta w / \beta^{c} .
$$

In the case where a stock-out occurs, demand is given by $D_{1}\left(p_{1}, h_{1}\right)=a_{1}-p_{1}-h_{1}$, and the intersection with the competitive supply gives a market price equal to $p_{1}^{c}=\beta^{c} \cdot\left(a_{1}-h_{1}\right)$. Inventories carried forward are $h_{2}=0$, and $p_{1}^{c}>p_{u}^{c}$ is required:

$$
\beta^{c}\left(a_{1}-h_{1}\right)>\delta \beta^{c} E(a)-\delta w,
$$

or

$$
a_{1}>\delta E(a)+h_{1}-\delta w / \beta^{c} .
$$

In the case in which smoothing occurs, using (38) in (2) we have

$$
h_{2}=E(a)-\left(w+\frac{p_{1}}{\delta}\right) / \beta^{c} .
$$

Equating supply with demand in the smoothing region yields

$$
p_{1} / c=a_{1}+E(a)-w / \beta^{c}-p_{1} /\left(\delta \beta^{c}\right)-p_{1}-h_{1}
$$

or

$$
p_{1}^{c}=\frac{\delta \beta^{c}\left(a_{1}-h_{1}+E(a)\right)-\delta w}{1+\delta}
$$

The quantity carried forward by speculators is then equal to

$$
h_{2}^{c}=E(a)-\left(w+\frac{\beta^{c}}{1+\delta}\left(a_{1}+E(a)-h_{1}-w / \beta^{c}\right)\right) / \beta^{c}
$$

which yields the second period price

$$
p_{2}^{c}=\beta^{c} a_{2}+\frac{\beta^{c}\left(a_{1}-h_{1}-\delta E(a)\right)+\delta w}{1+\delta}
$$




\section{B Proof of proposition 2}

The proof proceeds by finding regions of $\left(a_{1}, h_{1}\right)$ in which interior solutions to the three alternative profit functions in (43) are feasible. Since each of these functions is declining in $p_{1}$, we then examine what happens at the two thresholds to determine the global maximum.

\section{B.1 Characterizing interior solutions}

We examine the problems of maximizing (40), (41), and (42) in turn:

Stock-out: An interior solution to the problem of maximizing (40) results in

$$
p_{1}^{3}=\beta^{m}\left(a_{1}-h_{1}\right) .
$$

In order for an interior solution to be feasible in this region, $p_{1}^{3} \leq p_{u}^{m}$ must hold, i.e., $\beta^{m}\left(a_{1}-h_{1}\right) \geq \delta \beta^{m} E(a)-\delta w$, or

$$
a_{1}-h_{1}-\delta E(a)+\delta \frac{w}{\beta^{m}} \geq 0
$$

If condition (50) is satisfied, then there is a local maximum of the profit such that a stock-out occurs in period 1.

Smoothing: An interior solution to the problem of maximizing (41) must satisfy the first order condition:

$\frac{\delta\left(\beta^{m}\right)^{2}+2 \beta^{m}-1}{\left(1-\beta^{m}\right) \delta \beta^{m}}\left(a_{1}-h_{1}+E(a)\right)+\frac{(1+\delta)\left(1-2 \beta^{m}\right)}{\left(1-\beta^{m}\right) \delta\left(\beta^{m}\right)^{2}} w-\frac{(1+\delta)\left(\delta\left(\beta^{m}\right)^{2}+2 \beta^{m}-1\right)}{\left(1-\beta^{m}\right)\left(\delta \beta^{m}\right)^{2}} p_{1}=0$

which produces

$$
p_{1}^{2}=\frac{\delta \beta^{m}}{1+\delta}\left(a_{1}-h_{1}+E(a)\right)+\frac{\delta\left(1-2 \beta^{m}\right)}{\delta\left(\beta^{m}\right)^{2}+2 \beta^{m}-1} w .
$$

This price belongs to $\left[p_{l}^{m}, p_{u}^{m}\right]$ if and only if $p_{1}^{2} \leq p_{u}^{m}$ and $p_{1}^{2} \geq p_{l}^{m}$ or,

$$
a_{1}-h_{1}-\delta E(a)+\frac{\delta \beta^{m}(1+\delta)}{\delta\left(\beta^{m}\right)^{2}+2 \beta^{m}-1} w \leq 0
$$

and

$$
a_{1}-h_{1}-\delta E(a)+(1+\delta) \bar{h}+\frac{\delta \beta^{m}(1+\delta)}{\delta\left(\beta^{m}\right)^{2}+2 \beta^{m}-1} w \geq 0 .
$$

If conditions (51) and (52) are satisfied, then there is a local maximum of the profit such that smoothing occurs. 
Capacity: An interior solution to the problem of maximizing (42) results in

$$
p_{1}^{1}=\beta^{m}\left(a_{1}-h_{1}+\bar{h}\right) .
$$

To be feasible in the capacity regime, $p_{1}^{1}<p_{l}^{m}$ must hold, i.e., $\beta^{m}\left(a_{1}-h_{1}+\bar{h}\right) \leq$ $\delta \beta^{m} E(a)-\delta \beta^{m} \bar{h}-\delta w$, or

$$
a_{1}-h_{1}+(1+\delta) \bar{h}-\delta E(a)+\delta \frac{w}{\beta^{m}} \leq 0 .
$$

If condition (53) is satisfied, then there is a local maximum of the total profit in which speculators store up to capacity in period 1.

\section{B.2 Finding the global maximum}

Due to the continuity of the total profit, and to the linearity of the marginal profit in each of the three regions, finding the global optimum of this profit can be done by inspecting the position of each local optimum with respect to the bounds of its region, $p_{l}^{m}$ and $p_{u}^{m}$. However due to the discontinuity of the marginal profit, it is possible for $p_{l}^{m}$ or $p_{u}^{m}$ to be

the global optimum of the profit. Assumption 2 rules out some of the potential cases, as we shall now establish. To simplify the analysis, let us rewrite conditions (53), (51), (52) and (50) using the following notations. Let

$$
A \equiv a_{1}-h_{1}-\delta E(a) \text { and } K\left(\beta^{m}, \delta\right) \equiv \frac{\delta \beta^{m}(1+\delta)}{\delta\left(\beta^{m}\right)^{2}+2 \beta^{m}-1},
$$

then condition (53) becomes

$$
A+(1+\delta) \bar{h}+\frac{\delta}{\beta^{m}} w \leq 0
$$

condition (51) becomes

$$
A+K\left(\beta^{m}, \delta\right) w \leq 0
$$

condition (52) becomes

$$
A+(1+\delta) \bar{h}+K\left(\beta^{m}, \delta\right) w \geq 0,
$$

and condition (50) becomes

$$
A+\frac{\delta}{\beta^{m}} w \geq 0
$$

Since $\beta^{m} \in[1 / 2,1]$, it is clear that the denominator of $K\left(\beta^{m}, \delta\right)$ is strictly positive for any value $\delta \in[0,1]$. Consequently, 


$$
\begin{aligned}
\frac{\delta \beta^{m}(1+\delta)}{\delta\left(\beta^{m}\right)^{2}+2 \beta^{m}-1} & \geq \frac{\delta}{\beta^{m}} \Leftrightarrow \\
\left(\beta^{m}\right)^{2}(1+\delta) & \geq \delta\left(\beta^{m}\right)^{2}+2 \beta^{m}-1 \Leftrightarrow \\
\left(\beta^{m}-1\right)^{2} & \geq 0
\end{aligned}
$$

which always holds. Therefore $K\left(\beta^{m}, \delta\right) \geq \frac{\delta}{\beta^{m}}$ and we obtain the following ranking

$$
A+\frac{\delta}{\beta^{m}} w \leq A+K\left(\beta^{m}, \delta\right) w \leq A+(1+\delta) \bar{h}+K\left(\beta^{m}, \delta\right) w .
$$

Similarly

$$
A+\frac{\delta}{\beta^{m}} w \leq A+(1+\delta) \bar{h}+\frac{\delta}{\beta^{m}} w \leq A+(1+\delta) \bar{h}+K\left(\beta^{m}, \delta\right) w .
$$

and to rank conditions (53) to (50) it remains to compare $A+(1+\delta) \bar{h}+\frac{\delta}{\beta^{m}} w$ with $A+K\left(\beta^{m}, \delta\right) w$. We have

$$
A+K\left(\beta^{m}, \delta\right) w \leq A+(1+\delta) \bar{h}+\frac{\delta}{\beta^{m}} w \Leftrightarrow\left(\frac{\delta \beta^{m}(1+\delta)}{\delta\left(\beta^{m}\right)^{2}+2 \beta^{m}-1}-\frac{\delta}{\beta^{m}}\right) w \leq(1+\delta) \bar{h} .
$$

If Assumption 2 holds then

$$
A+\frac{\delta}{\beta^{m}} w \leq A+K\left(\beta^{m}, \delta\right) w \leq A+(1+\delta) \bar{h}+\frac{\delta}{\beta^{m}} w \leq A+(1+\delta) \bar{h}+K\left(\beta^{m}, \delta\right) w
$$

In this case, we can determine the global maximum as follows:

1. If $0 \leq A+\frac{\delta}{\beta^{m}} w$ then the profit is strictly increasing for $p_{1} \leq p_{l}^{m}$, strictly increasing for $p_{1} \in\left[p_{l}^{m}, p_{u}^{m}\right]$ and has a local maximum at $p_{1}^{3}>p_{u}^{m}$. By continuity of the profit, the price chosen by the monopoly is

$$
p_{1}^{*}=p_{1}^{3}=\beta^{m}\left(a_{1}-h_{1}\right) .
$$

The condition under which this price is the optimum of the monopolist can be rewritten

$$
0 \leq A+\frac{\delta}{\beta^{m}} w \Leftrightarrow \beta^{m}\left(a_{1}-h_{1}-\delta E(a)\right)+\delta w \geq 0 \Leftrightarrow \frac{\partial \Pi_{1}^{1}}{\partial p_{1}}\left(p_{u}^{m}\right) \geq 0 .
$$

2. If $A+\frac{\delta}{\beta^{m}} w \leq 0 \leq A+K\left(\beta^{m}, \delta\right) w$, then the profit is strictly increasing for $p_{1} \leq p_{u}^{m}$ and strictly decreasing for $p_{1} \geq p_{u}^{m}$. The global optimum is therefore

$$
p_{1}^{*}=p_{u}^{m}=\delta \beta^{m} E(a)-\delta w .
$$

The first condition under which this price is the optimum is equivalent to $\frac{\partial \Pi_{1}^{1}}{\partial p_{1}}\left(p_{u}^{m}\right)<$ 0 , and it is immediate to verify that the second one is equivalent to $\frac{\partial \Pi_{1}^{2}}{\partial p_{1}}\left(p_{u}^{m}\right) \geq 0$. 
3. If $A+K\left(\beta^{m}, \delta\right) w \leq 0 \leq A+(1+\delta) \bar{h}+\frac{\delta}{\beta^{m}} w$ then the profit is strictly increasing for $p_{1} \leq p_{l}^{m}$, strictly decreasing for $p_{1} \geq p_{u}^{m}$ and has a global maximum at

$$
p_{1}^{*}=p_{1}^{2}=\frac{\delta \beta^{m}}{1+\delta}\left(a_{1}-h_{1}+E(a)\right)+\frac{\delta\left(1-2 \beta^{m}\right)}{\delta\left(\beta^{m}\right)^{2}+2 \beta^{m}-1} w .
$$

The first condition is equivalent to $\frac{\partial \Pi_{1}^{2}}{\partial p_{1}}\left(p_{u}^{m}\right)<0$. We leave the second condition for next case.

4. If $A+(1+\delta) \bar{h}+\frac{\delta}{\beta^{m}} w \leq 0 \leq A+(1+\delta) \bar{h}+K\left(\beta^{m}, \delta\right) w$ then two solutions must be compared, namely $p_{1}^{3}$ and $p_{1}^{2}$. When the price is $p_{1}^{3}$, (42) produces

$$
\begin{aligned}
\Pi_{1}^{3}\left(p_{1}^{3}\right)= & \beta^{m}\left(1-\beta^{m}\right)\left(a_{1}-h_{1}+\bar{h}\right)^{2}-\frac{2 \beta^{m}-1}{2\left(1-\beta^{m}\right)}\left(1-\beta^{m}\right)^{2}\left(a_{1}-h_{1}+\bar{h}\right)^{2} \\
& +\delta E_{1}\left(\frac{1-\beta^{m}}{2}\left(a_{2}-\bar{h}\right)^{2}\right) \\
= & \frac{1-\beta^{m}}{2}\left(\left(a_{1}-h_{1}+\bar{h}\right)^{2}+\delta E\left[a^{2}\right]+\delta(E(a)-\bar{h})^{2}\right) .
\end{aligned}
$$

When the price is equal to $p_{1}^{2}$, (41) reduces to

$$
\Pi_{1}^{2}\left(p_{1}^{2}\right)=\frac{1-\beta^{m}}{2}\left(\frac{\delta}{1+\delta}\left(a_{1}-h_{1}+E(a)\right)^{2}+\frac{\delta^{2}}{\left(\delta\left(\beta^{m}\right)^{2}+2 \beta^{m}-1\right)} w^{2}+\delta E\left[a^{2}\right]\right) .
$$

Comparing $\Pi_{1}^{3}\left(p_{1}^{3}\right)$ and $\Pi_{1}^{2}\left(p_{1}^{2}\right)$ we have:

$$
\Pi_{1}^{3}\left(p_{1}^{3}\right)-\Pi_{1}^{2}\left(p_{1}^{2}\right) \geq 0
$$

if

$$
\left(a_{1}-h_{1}+\bar{h}\right)^{2}+\delta(E(a)-\bar{h})^{2} \geq \frac{\delta}{1+\delta}\left(a_{1}-h_{1}+E(a)\right)^{2}+\frac{\delta^{2}}{\delta\left(\beta^{m}\right)^{2}+2 \beta^{m}-1} w^{2} .
$$

Replacing $a_{1}-h_{1}+\bar{h}$ by $a_{1}-h_{1}+E(a)-E(a)+\bar{h}$ in the left-hand-side and developing gives:

$$
\begin{array}{r}
\left(a_{1}-h_{1}+E(a)\right)^{2}-2\left(a_{1}-h_{1}+E(a)\right)(E(a)-\bar{h})+(E(a)-\bar{h})^{2}+\delta(E(a)-\bar{h})^{2} \\
\geq \frac{\delta}{1+\delta}\left(a_{1}-h_{1}+E(a)\right)^{2}+\frac{\delta^{2}}{\delta\left(\beta^{m}\right)^{2}+2 \beta^{m}-1} w^{2}
\end{array}
$$

which is equivalent to

$$
\begin{array}{r}
\frac{\left(a_{1}-h_{1}+E(a)\right)^{2}}{1+\delta}-2\left(a_{1}-h_{1}+E(a)\right)(E(a)-\bar{h})+(1+\delta)(E(a)-\bar{h})^{2} \\
\geq \frac{\delta^{2}}{\delta\left(\beta^{m}\right)^{2}+2 \beta^{m}-1} w^{2}
\end{array}
$$


giving

$$
\left(\frac{a_{1}-h_{1}+E(a)}{\sqrt{1+\delta}}-\sqrt{1+\delta}(E(a)-\bar{h})\right)^{2} \geq \frac{\delta^{2}}{\delta\left(\beta^{m}\right)^{2}+2 \beta^{m}-1} w^{2} .
$$

The difference between $\Pi_{1}^{3}\left(p_{1}^{3}\right)$ and $\Pi_{1}^{2}\left(p_{1}^{2}\right)$ is positive if and only if

$$
\begin{gathered}
\left(\frac{a_{1}-h_{1}+E(a)}{\sqrt{1+\delta}}-\sqrt{1+\delta}(E(a)-\bar{h})-\frac{\delta w}{\sqrt{\delta\left(\beta^{m}\right)^{2}+2 \beta^{m}-1}}\right) \times \\
\left(\frac{a_{1}-h_{1}+E(a)}{\sqrt{1+\delta}}-\sqrt{1+\delta}(E(a)-\bar{h})+\frac{\delta w}{\sqrt{\delta\left(\beta^{m}\right)^{2}+2 \beta^{m}-1}}\right) \geq 0 .
\end{gathered}
$$

If $a_{1}-h_{1}+E(a) \leq(1+\delta)(E(a)-\bar{h})-\frac{\delta \sqrt{1+\delta}}{\sqrt{\delta\left(\beta^{m}\right)^{2}+2 \beta^{m}-1}} w$, then both terms of the product above are negative and the product is positive, if $a_{1}-h_{1}+E(a) \geq(1+\delta)(E(a)-\bar{h})-$ $\frac{\delta \sqrt{1+\delta}}{\sqrt{\delta\left(\beta^{m}\right)^{2}+2 \beta^{m}-1}} w$ and $a_{1}-h_{1}+E(a) \leq(1+\delta)(E(a)-\bar{h})+\frac{\delta \sqrt{1+\delta}}{\sqrt{\delta\left(\beta^{m}\right)^{2}+2 \beta^{m}-1}} w$, then one term is positive, the other is negative, and the product is negative. Finally if $a_{1}-h_{1}+E(a) \geq(1+\delta)(E(a)-\bar{h})+\frac{\delta \sqrt{1+\delta}}{\sqrt{\delta\left(\beta^{m}\right)^{2}+2 \beta^{m}-1}} w$ then both terms of the product are positive and the product is positive. The initial conditions on parameters such that two local maxima co-exist can be rewritten:

$$
A+(1+\delta) \bar{h}+\frac{\delta}{\beta^{m}} w \leq 0 \Leftrightarrow a_{1}-h_{1}+E(a) \leq(1+\delta)(E(a)-\bar{h})-\frac{\delta}{\beta^{m}} w
$$

and

$0 \leq A+(1+\delta) \bar{h}+K\left(\beta^{m}, \delta\right) w \Leftrightarrow a_{1}-h_{1}+E(a) \geq(1+\delta)(E(a)-\bar{h})-K\left(\beta^{m}, \delta\right) w$.

Since $K\left(\beta^{m}, \delta\right)$ is positive, $(1+\delta)(E(a)-\bar{h})-K\left(\beta^{m}, \delta\right) w<(1+\delta)(E(a)-\bar{h})+$ $\frac{\delta \sqrt{1+\delta}}{\sqrt{\delta\left(\beta^{m}\right)^{2}+2 \beta^{m}-1}} w$, and it suffices to compare the lower bound of the two inequalities above, $(1+\delta)(E(a)-\bar{h})-\frac{\delta}{\beta^{m}} w$, with the lowest root of the product $(1+\delta)(E(a)-$ $\bar{h})-\frac{\delta \sqrt{1+\delta}}{\sqrt{\delta\left(\beta^{m}\right)^{2}+2 \beta^{m}-1}} w$ to end up the characterization of the global maximum. Here,

$$
-\frac{\delta}{\beta^{m}} w \geq-\frac{\delta \sqrt{1+\delta}}{\sqrt{\delta\left(\beta^{m}\right)^{2}+2 \beta^{m}-1}} w
$$

is equivalent to

$$
\beta^{m} \sqrt{1+\delta} \geq \sqrt{\delta\left(\beta^{m}\right)^{2}+2 \beta^{m}-1} \Leftrightarrow\left(\beta^{m}\right)^{2}-2 \beta^{m}+1 \geq 0
$$

which always holds. Therefore the sign of the difference of the profits is always negative in the region considered and the global optimum is $p_{1}^{2}$. 
5. Finally, if $A+(1+\delta) \bar{h}+K\left(\beta^{m}, \delta\right) w \leq 0$ then the profit has a global maximum for

$$
p_{1}^{3}=\beta^{m}\left(a_{1}-h_{1}+\bar{h}\right) \text {. }
$$

The condition leading to this case is that $\frac{\partial \Pi_{1}^{3}}{\partial p_{1}}\left(p_{l}^{m}\right)<0$.

\section{References}

[1] Anderson, R. W., And Gilbert, C. L. Commodity agreements and commodity markets: Lessons from tin. The Economic Journal 98, 389 (Mar. 1988), 1-15.

[2] Deaton, A., and Laroque, G. On the behavior of commodity prices. Review of Economic Studies 59 (1992), 1-23.

[3] Deaton, A., and Laroque, G. Competitive storage and commodity price dynamics. Journal of Political Economy 104, 5 (1996), 896-923.

[4] Energy Information Association. U.S. underground natural gas storage developments: 1998-2005, October 2006.

[5] Galassi, M., Davies, J., Theiler, J., Gough, B., Jungman, G., Booth, M., AND Rossi, F. GNU Scientific Library Reference Manual (2nd Ed.). ISBN $0954161734,2006$.

[6] Judd, K. L. Numerical Methods in Economics. The MIT Press, Cambridge, Massachusetts, 1998.

[7] McLaren, J. Speculation on primary commodities: The effects of restricted entry. Review of Economic Studies 66 (1999), 853-71.

[8] Miranda, M. J., And Fackler, P. L. Applied Computational Economics and Finance. MIT Press, 2002.

[9] Newbery, D. M. Commodity price stabilization in imperfect or cartelized markets. Econometrica 52, 3 (May 1984), 563-578.

[10] Newbery, D. M. G., And Stiglitz, J. E. The Theory of Commodity Price Stabilization: A Study in the Economics of Risk. Oxford University Press, 1981.

[11] Samuelson, P. A. Stochastic speculative price. Proceedings of the National Academy of Sciences 68, 2 (February 1971), 335-337.

[12] Scheinkman, J. A., And Schechtman, J. A simple competitive model with production and storage. The Review of Economic Studies 50, 3 (Jul. 1983), 427-441. 
[13] Thille, H. Inventories, market structure, and price volatility. Journal of Economic Dynamics and Control 30, 7 (July 2006), 1081-1104.

[14] Williams, J. C., And Wright, B. D. Storage and Commodity Markets. Cambridge University Press, 1991. 